ments observed at Brazil by the Holland Commission. The last section is devoted to some miscellaneous data, and contains, among other matters, tables for determining, rapidly and approximately, the elements of a triangulation by the method proposed by Mr. Francis Galton.

\section{RECENT ADVANCES IN SCIENCE, AND THEIR BEARING ON MEDICINE AND SURGERY.}

THE honour of being invited to deliver the second Huxley Lecture has deeply moved me. How beautiful are these days of remembrance which have become a national custom of the English people! How touching is this act of gratitude when the celebration is held at the very place wherein the genius of the man whom it commemorates was first guided towards its scientific development ! We are filled not alone with admiration for the hero, but at the same time with grateful recognition of the institution which planted the seed of high achievement in the soul of the youthful student. That you, gentlemen, should have entrusted to a stranger the task of giving these feelings expression seemed to me an act of such kindly sentiment, implying such perfect confidence, that I at first hesitated to accept it. How am I to find in a strange tongue words which shall perfectly express my feelings? How shall $I$, in the presence of a circle of men who are personally unknown to me, but of whom many knew him who has passed away and had seen him at work, always find the right expression for that which I wish to say as well as a member of that circle itself could ? I dare not believe that I shall throughout succeed in this. But if, in spite of all, I repress my scruples it is because I know how indulgently my English colleagues will judge my often incomplete statements, and how fully they are inclined to pardon deficiency in diction if they are convinced of the good intentions of the lecturer.

\section{Professor Huxley's WORK.}

I may assume that such a task would not have been allotted to me had not those who imposed it known how deeply the feeling of admiration for Huxley is rooted within me, had they not seen how fully I recognised the achievements of the dead master from his first epoch-making publications, and how greatly I prized the personal friendship which he extended towards me. In truth, the lessons that I received from him in his laboratorya very modest one according to present conditions-and the introduction to his work which I owe to him, form one of the pleasantest and most lasting recollections of my visit to Kensington. The most competent witness of Huxley's earliest period of development, Prof. Foster, presented in the first of these lectures a picture of the rapidly increasing extension of the biological knowledge, which must have excited not only our admiration, but also the emulation of all who study medicine. Upon me the duty is incumbent of incorporating with this presentment the newer strides of knowledge and of stating their influence upon the art of healing. So great a task is this that it would be presumptuous even to dare to attempt its accomplishment in a single lecture. I have decided, therefore, that I must confine myself to merely sketching the influence of biological discoveries upon medicine. In this way also will the example of Huxley be most intelligible to us. I must here make a confession. When I tried to ascertain how much time would be required to deliver my lecture as I had prepared it, I found, to my regret, that its delivery would occupy nearly double the time assigned to me. I had therefore to reduce it to about half of its original dimensions. This could only be done by means of very heroic cuts, seriously damaging in more than one place my chain of ideas. If, therefore, you should find, gentlemen, that my transitions from one point to the other occasionaliy are of a somewhat sudden and violent character, I trust you will bear with me and remember that, if you should take the trouble of reading my address afterwards, you will be less shocked than you may be to-day by my statements when they appear in print.

\section{The Beginnings of Biology,}

Huxley himself, though trained in the practical school of Charing-cross Hospital, won his special title to fame in the domain of biology. As a matter of fact, at that time even the

I The second Huxley lecture, delivered by Prof. R. Virchow at the opening of the winter session of Charing Cross Hospital Medical School, on October 3. Reprinted from the Times.

NO. I 5 IO, VOL. 58] name of biology had not come into general use. It was only recently that the idea of life itself obtained its full significance. Even in the late middle ages it had not sufficient strength to struggle through the veil of dogmatism into the light. I am glad to be able to-day for the second time to credit the English nation with the service of having made the first attenıpts to define the nature and character of life. It was. Francis Glisson, who, following expressly in the footsteps of Paracelsus, investigated the principium vita. If he could not elucidate the nature of life, he at least recognised its main characteristic. This is what he was the first to describe as "irritability," the property on which the energy of living matter depends. How great was the step from Paracelsus to Glisson, and-we may continue-from Glisson to Hunter! According to Paracelsus, life was the work of a special spiritus, which set material substance in action, like a machine; for Glisson, matter itself was the principium energeticum. Unfortunately, he did not confine this dictum to living substances only, but applied it to substance in general, to all matter. It was Hunter who first announced the specific nature of living matter as contrasted with non-living, and he was led to place a materia vita diffusa at the head of his physiological and pathological views. According to the teaching of Hewson and Hunter, the blood supplied the plastic materials of physiology as well as the plastic exudates of pathology. Such was the basis of the new biolngical method, if one can apply such an expression to a still incomplete doctrine, in 1842 , when Huxley was beginning his medical studies at Charing-cross Hospital. It would lead too far afield were I to recount in this place how it happened that I myself, like Huxley, was early weaned from the pernicious doctrines of humoral pathology.

\section{The Development of Biology.}

When Huxley himself left Charing-cross Hospital, in $\mathbf{1 8 4 6}$, he had enjoyed a rich measure of instruction in anatomy and physiology. Thus trained, he took the post of naval surgeon, and by the time that he returned, four years later, he had become a perfect zoologist and a keen-sighted ethnologist. How this was possible, any one will readily understand who knows from his own experience how great the value of personal observation is for the development of independent and unprejudiced thought. For a young man who, besides collecting. a rich treasure of positive knowledge, has practised dissection and the exercise of a critical judgment, a long sea-voyage and a peaceful sojourn among entirely new surroundings afford an invaluable opportunity for original work and deep reflection. Freed from the formalism of the schools, thrown upon the use of his own intellect, compelled to test each single object as regards properties and history, he saon forgets the dogmas of the prevailing system and becones first a sceptic, and then an investigator. This change, which did not fail to affect Huxley, and through which arose that Huxley whom we commemorate to-day, is no unknown occurrence to one who is acquainted with the history, not only of knowledge, but also of scholars. We need only point to John Hunter and Darwin as closelyallied examples. The path on which these men have achieved their triumphs is that which biology in general has trodden with ever-widening strides since the end of last century-it is the path of genetic investigation. We Germans point with pride to our countryman who opened up this road with full conviction of its importance, and who directed towards it the eyes of the world-our poet-prince Goethe. What he accomplished in particular from plants others of our fellow-countrymen achieved from animals-Wolf, Meckel, and our whole embryological school. As Harvey, Haller, and Hunter had once done, so these men began also with the study of the "ovulum," but this very soon showed that the egg was itself organised, and that from it arose the whole series of organic developments. When Huxley, after his return, came to publish his fundamental observations he found the history of the progressive trans. formations of the contents of the egg already verified; for it was by now known that the egg was a cell, and that from it fresh cells, and from them organs, arose. The second of his three famous papers-that on the relationship between man and the animals next beneath him-limned in exemplary fashion the parallelism in the earliest development of all animal beings. But beyond this it stepped boldly across the border-line which tradition and dogma had drawn between man and beast. Huxley had no hesitation in filling the gaps which Darwin had left in his argument, and in explaining that "in respect of 
substance and structure man and the lower animals are one." Whatever opinion one may hold as to the origin of mankind, the conviction as to the fundamental correspondence of human organisation with that of animals is at present universally accepted.

\section{Omais Cellula e Cellula.}

The greatest difficulty in the advance of biology has been the natural tendency of its disciples to set the search after the unity of life in the forefront of their inquiries. Hence arose the doctrine of vital force, an assumption now discarded, but still revealing its influence from time to time in isolated errors. No satisfactory progress can be made till the idea of highly organised living things as units had been set aside; till it was recognised that they were in reality organisms, each constituent part of which had its special life. Ultimate analysis of higher animals and plants brings us alike to the cell; and it is these single parts, the cells, which are to be regarded as the factors of existence. The discovery of the development of complete beings from the ova of animals and the germ-cells of plants has bridged the gap between isolated living cells and complete organisms, and has enabled the study of the former to be employed in elucidating the life of the latter. In a medical school where the teaching is almost exclusively concerned with haman beings this sentence should be writ large:-"The organism is not an individual, but a social mechanism." Two corollaries must also be stated-(I) that every living organism, dike every organ and tissue, contains cells; $(2)$ that the cells are composed of organic chemical substances, which are not themselves alive. The progress of truth in these matters was much retarded hy that portion of Schwann's cell-thenry which sought to establish the existence of free cell-formation, which really implied the revival of the old doctrine of spontaneous generation. This belief was gradually driven out of the domain of zoology, but in connection with the formation of plastic exudates found a sanctuary in that of pathology. I myself was taught the discontinuity of pathological growths-a view which would logically lead back to the origin of living from non-living matter. But enlightenment in this matter came to me. At the end of my academical career I was acting as clinical assistant in the eye department of the Berlin Hospital, and I was struck by the fact that keratitis and corneal wounds healed without the appearance of plastic exudation, and I was thus led to study the process of inflammation in other non. vascular structures, such as articular cartilages and the intima of the larger vessels. In no one of these cases was plastic exuda. tion found, but in all of them were changes in the tissue cells. Turning next to vascular organs, and in particular those which are the common seats of exudation processes, I succeeded in demonstrating that the presence of cells in inflammatory exudates was not the result of exudation, but of multiplication of preexisting cells. Extending this to the growth in thickness of the long bones-which was ascribed by Duhamel to organisation of a nutricious juice exuded by the periosteal vessels-I was thus eventually able to extend the biological doctrine of ommis cellula e cellula to pathological processes as well ; every new formation presupposing a matrix or tissue from which its cells arise and the stamp of which they bear.

\section{HEREDITY.}

Herein also lies the key to the mystery of heredity. The humoral theory attributed this to the blood, and based the most fantastic ideas upon this hypothesis; we know now that the cells are the factors of the inherited properties, the sources of the germs of new tissues and the motive power of vital action. It must not, however, be supposed that alt the problems of heredity have thus been.solved. Thus, for instance, a general explanation of theromorphism, or the appearance of variations recalling the lower animals, is still to be found. Each case must be studied on its merits, and an endeavour made to discover whether it arose by atavism or by hereditary transmission of an acquired condition. As to the occurrence of the latter mode of origin, I can express myself positively. Equally difficult is the question of hereditary diseases; this is now generally assumed to depend on the transmission of a predisposition which is present, though not recognisable, in the earliest cells, being derived from the paternal or maternal tissues. But the most elaborately constructed doctrines as to the hereditariness of a given disorder may break down before the discovery of an actual causa viva. A notable example of this is found in the case of leprosy, the

$$
\text { NO. I } 5 \text { IO, VOL. } 58 \text { ] }
$$

transmission of which by inheritance was at one time so firmly believed in that thirty years ago a law was nearly passed in Norway forbidding the marriage of members of leprous families. I myself, however, found that a certain number of cases at any rate did not arise in this way, and my results were confirmed by the discovery of the leprous bacillus by Armauer Hansen. In a moment the hereditary theory of the disease was overthrown and the old view of its acquirement by contagion restored. Precisely the same happened a few decades earlier with regard to favus and scabies. Another instructive condition is that known as Heterotopia in which fragments of tissues or organs are found dwelling in a situation other than that which is normal to them. This is particularly the case with certain glands, such as the thyroid and suprarenal, but is also known with cartilage, teeth, and the various constituents of dermoids. It no doubt occurs by process of transplantation, the misplaced tissues developing no new properties, but merely preserving their normal powers of growth. The attempt to generalise from this fact and to attribute all tumour-formation to this cause carries the idea beyond its proper scientific limits.

\section{Parasitism AND INFECTION.}

With regard to the subject of parasitism, the progress or scientific observation was retarded for centuries by the prevalence of the assumption made by Paracelsus that disease in general was to be regarded as a parasite. Pushed to its logical conclusion, this view would imply that each independent living part of the organism would act as a parasite relatively to the others. The true conception of a parasite implies its harmfulness to its host. The larger animal parasites have been longest known, but it is not so many years since their life-history has been completely ascertained and the nature of their cysts explained, while an alternation of generations has been discovered in those which are apparently sexless. Very much more recent is the detection of the parasitic protozoa, by which the occurrence of the tropical fevers may be explained. As yet we have not complete knowledge as to their life-history, but we hold the end of the chain by which this knowledge can be attained. The élite of the infectious diseases are, however, the work of the minutest kind of parasitic plants, bacteria, the scientific study of which may be said to date from Pasteur's immortal researches upon putrefaction and fermentation. The observation of microbes under exact experimental conditions, and the chemical investigation of their products opened up the modern field of bacteriology, a science among the early triumphs of which were the discoveries of the bacilli of tubercle and Asiatic cholera by Robert Koch. In connection with this subject, three important landmarks require comment. One is the necessity for distinguishing between the cause and the essential nature of infectious diseases, the latter of which is determined by the reaction of the tissues and organs to microbes. Secondly, there is the relation between the smaller parasites and the diseases determined by them. This may be summed up in the general word (introduced by Prof. Virchow himself) "infection." But to assume that all infections result from the action of bacteria is to go beyond the domain of present knowledge, and probably to retard further progress. The third point is the question as to the mode of action of infection. It is only the larger parasites whose main effect is the devouring of parts of their hosts; the smaller act mainly by the secretion of virulent poisons. The recognition of this latter fact has led to the brilliant work of Lister on the one hand, and to the introduction of serum-therapeutics on the other.

\section{Antiseptic Surgery.}

It would be carrying coals to Newcastle were I to sketch in London the beneficial effects which the application of methods of cleanliness has exercised upon surgical practice. In the city wherein the man still lives and works who, by devising this treatment, has introduced the greatest and most beneficent reform that the practical branches of medical science have ever known, every one is aware that Lord Lister; on the strength of his original reasoning, arrived at practical results which the new theory of fermentative and septic processes fully confirmed. Before any one had succeeded in demonstrating by exact methods the microbes which are active in different diseases, Lister had learnt, in a truly prophetic revelation, the means by which protection against the action of putrefactive organisms can be attained. The opening up of further regions of clinical medicine to the knife of the surgeon and a perfect revolution in 
the basis of therapeutics have been the consequence. Lord Lister, whom I am proud to be able to greet as an old friend, is already and always will be reckoned amongst the greatest benefactors of the human race. May he long be spared to remain at the head of the movement which he called into existence.

\section{Artificial Immunisation.}

It remains for me to say a word concerning the other great problem, the solution of which the whole world is awaiting with anxious impatience. I refer to the problem of immunity and its practical corollary, artificial immunisation. It has already happened once that an Englishman has succeeded in applying this to the definite destruction of at least one of the most deadly infectious diseases. Jenner's noble discovery has stood its trial as successfully, except in popular fancy, as he hoped. Vaccine is in all hands ; vaccination is, with the aid of Governments, spreading continually. Pasteur also laboured with determination; others have followed him, and the new doctrine of antitoxins is continually acquiring more adherents. But it has not yet emerged from the $\mathrm{c}$ inflict of opinions, and still less is the secret of immunity itself revealed. We must become well accustomed to the thought that only the next century can bring light and certainty on this point. Prof. Virchow, having referred with pride to the influence of cellular pathology in modern treatment, entailing, as it does, the principle of destroying the focus of disease by early operation, concluded his lecture in these words:-May the Medical School of Charing-cross Hospital continue upon the newly-opened path with zeal and good fortune. But may its students at the same time never forget that neither the physician nor the naturalist dares to dispense with a cool head and a calm spirit, with practical observation and critical judgment.

\section{CHEMISTRY AT THE BRITISH ASSOCIATION.}

A LTHOUGH no epoch-making discoveries can be recorded amongst the contributions to the Chemical Section this year, the work of the Section was full of interest and attraction. A very wide range of subjects was included in the programme, and the presence of many past-presidents of the Section added very considerably to the success of the meeting. The announcement of the discovery of two new elements, Monium and Xenon, must constitute a record for the first two days of the meeting, although new elements, especially amongst the rarer earths and gases, hardly excite the interest that similar discoveries did some years back. Monium is described in Sir William Crookes' address. It is an added element culled "from the waste heaps of the mineral elements," characterised by a group of distinctive lines in the ultra-violet end of the spectrum, and having an atomic weight of about II8, between those accepted for yttrium and lanthanum respectively. "Xenon" was described by Prof. Ramsay and Dr. Travers in their paper on " The extraction from air of the companions of Argon and on Neon." It accompanies krypton and metargon in the last fractions of liquefied argon, and is easily separated from the latter on account of its higher boiling point. It remains behind after the other two gases have evaporated, and is the heaviest of the three gases. Xenon, "the stranger," shows an analogous spectrum to argon, but differing entirely in the position of the lines. With the ordinary discharge the gas shows three lines in the red, and about five very brilliant lines in the blue; while with the jar and spark-gap these lines disappear, and are replaced by four brilliant lines in the green, intermediate in position between the two groups of argon lines. The remainder of the paper dealt with the successful issue of the search for "an undiscovered gas"- the subject of Prof. Ramsay's presidential address to the Section at Toronto. This gas should have an atomic weight higher than that of helium by about 16 units, and lower than that of argon by about 20 . The determination of the atomic weight of neon gave the figure 19.2 it would therefore follow fluorine, and precede sodium in the periodic table. Like argon and helium it is monatomic; it is present in the air in the proportion of about I part in 40,000. Prof. Emerson Reynolds added a note on the position of helium, argon, krypton and neon in his diagrammatic representation of the relations of the elements, and pointed out that their atomic weights as yet determined were well in accord with his repre- sentation $O_{1}$ the periodje law. Amongst other papers on inorganic chemistry, Prof. F. Clowes gave an account of his work on the action of magnesium on cupric sulphate solutions, under the title of "Equivalent replacement of metals." The reaction was studied with both hot and cold solutions, and under various conditions of concentration. In all cases cuprous oxide is formed, and hydrogen is evolved side by side with the deposition of the copper. This evolution of hydrogen is attributed in part, but not wholly, to the presence of free sulphuric acid formed by hydrolysis of the cupric sulphate and accompanied by the separation of a basic salt. Prof. Hodgkinson and Mr. Coote, in a paper on "Alkaline chlorates and sulphates of the heavy metals," pointed out that many solid sulphates, whether containing water of crystallisation or anhydrous, give off chlorine in addition to oxygen when gently beated with potassium or sodium chlorate. A residue of the alkaline sulphate and chloride and the oxide and chloride of the metal is left hehind. The evolution of chlorine and oxygen occurs at temperatures very little above $100^{\circ}$ C. Mr. R. G. Durrant described a series of "Green cobaltic compounds" he had obtained by oxidising potassium cobaltous oxalate with hydrogen peroxide; similar results follow the oxidation of cobaltous salts in presence of glycollates, citrates, malates, lactates or succinates of the alkali metals.

In another branch of the science, physical chemistry, Prof. Sydney Young contributed a most licid and interesting account of his researches on the "Thermal properties of gases and liquids." The subject is one which has engaged Prof. Young's attention for the past eleven years, and his descriptive summary of his labours was therefore received with special interest. One chief aim of these investigations has been to ascertain whether the generalisations of Van der Waals regarding the relations of pressure, temperature and volume for both gases and liquids, are really true, and if not, whether the observed deviations would throw any light on the modifications which must be made in Van der Waals's fundamental formula in order to bring it into accurate agreement with the experimentally determined isothermals for liquids and gases. The vapour pressures and specific volumes of a number of substances were therefore determined, both as liquid and as saturated vapour, from low temperatures to their critical points. Twenty-six substances have been examined altngether, including paraffins, benzene and its haloid derivatives, esters, alcohols and acetic acid, and the data obtained allow of a simple classification in respect to their physical constants. Amongst other points of interest the results show that the molecules of the alcohols at moderate temperatures are polymerised in the liquid, but not in the gaseous state, whilst there is polymerisation in both states in the case of acetic acid ; also, that the molecules of the alcohols and acetic acid appear to be polymerised to a considerable extent at the critical point. Prof. Young also described his methods for the determination of the critical constants and of the specific volumes of both liquid and saturated vapour. Ample proof was obtained in the course of these investigations that the views of Andrews regarding the behaviour of a substance in the neigh. bourhood of the critical point are correct, and also that the vapour pressure of a pure substance is quite independent of the relative volumes of liquid and vapour. The method of fractional distillation of liquids adopted for the preparation of pure substances was described, and the apparatus was exhibited at work; it has thus been found quite feasible to separate perfectly pure normal and iso-pentane from American petroleum. The Earl of Berkeley described the methods he has adopted for the more exact determination of the densities of crystals, in which special precautions are taken to eliminate errors in the measurement of temperature, volume and mass, occlusion of mother liquor, and absorption of moisture. The determinations recorded were made in carbon tetrachloride, a maximum divergence of 0.04 per cent. being shown as the result of four determinations of the density of potassium carbonate crystals. Under the head of phys. ical chemistry the joint-meeting with Section A on the "Results of the recent Eclipse expeditions," has been referred to in connection with the doings of the Physical Section. The modern photographic plate as a sensitive medium for the recording of chemical action was the subject of several interesting communications, notably that of Dr. W. J. Russell on "The action exerted by certain metals and other organic substances on a photographic plate." Some account of these researches has already been given in N.ATURE. Dr. Russell showed a series of slides illustrating the action of printer's ink, wood, dry

NO. I 5 IO, VOL. $5^{8}$ ] 